\title{
A aula universitária: onde ficam professor e aluno (?)
}

\section{The university class: where are the teacher and student (?)}

\author{
Bendita Donaciano Lopes ${ }^{1}$ \\ Fernanda Borges de Andrade ${ }^{2}$ \\ Naima de Paula Salgado Chaves ${ }^{3}$
}

\begin{abstract}
RESUMO
Este trabalho discute as características de uma boa aula no ensino superior, enfatizando o papel de seus protagonistas: professor e aluno. Parte do princípio de que ensinar e aprender são tarefas complexas que exigirão envolvimento e abertura para a construção do conhecimento. Trazemos, primeiramente, as principais características da aula no ensino superior como pressuposto da mudança de paradigma da centralidade do ensino no professor para a centralidade do ensino no aluno. Num segundo momento, tratamos do papel do professor e dos alunos no processo de ensino-aprendizagem reafirmando não haver exclusividade e nem centralidade nem em um nem no outro, por considerarmos ser a aula uma relação que permite a interação simultânea num espaço de diálogo consistente entre os envolvidos. Concluindo, reiteramos a concepção de conhecimento entendido como uma contínua reconstrução baseada em experiências de aprendizagem que justifiquem e requeiram novos modos de pensar, agir e conviver.
\end{abstract}

PALAVRAS-CHAVE: Aula universitária; Ensino centrado no professor; Ensino centrado no aluno.

\footnotetext{
1 Doutora em Educação na especialidade em Psicologia da Educação. Professora da Universidade Pedagógica, Maputo-Moçambique. Ph.D, Professora Auxiliar. /Pró-Reitora para a Graduação. Moçambique. Email: bdonaciano@up.ac.mz; donacianob@gmail.com; benditadonaciano@yahoo.com.br. 2 Doutoranda em Educação, PPGED/UFU. Professora Assistente da Universidade Federal do Triângulo Mineiro - UFTM. Brasil. E mail: feborgesaz@yahoo.com.br.

3 Doutoranda em Educação, PPGED/UFU. Pedagoga do Instituto Federal do Triângulo Mineiro IFTM. Professora/Pedagoga. Brasil. E mail: naima@iftm.edu.br
} 


\begin{abstract}
This paper discusses the characteristics of a good class in higher education, emphasizing the role of its protagonists: teacher and student. Assumes that teaching and learning are complex tasks that require involvement and openness for the construction of knowledge. We bring, first, the main characteristics of class in higher education from the assumption of the centrality of the paradigm shift in education teacher for the centrality of teaching the student. Secondly, the role of the teacher and the students in the teaching-learning process Reaffirming that there is no exclusivity and not centrality in a or the other, because we believe to be class a relationship that allows simultaneous interaction within a consistent dialogue between those involved. In conclusion, we reiterate the conception of knowledge understood as a continuous reconstruction based on learning experiences which justify and require new ways of thinking, acting and live.
\end{abstract}

KEYWORDS: College Class; Teacher-centered education; Studentcentered education.

\title{
Introdução
}

Este artigo tem como objetivo discutir as características de uma boa aula no ensino superior e, consequentemente, o papel do professor e do aluno em sua realização. Primeiramente, gostaríamos de assinalar que ensinar e aprender não são tarefas fáceis e exigem do professor e do aluno envolvimento, conhecimento, abertura e empenho.

A aula é o encontro em que se entrelaçam dois sujeitos: o professor, quem ensina, e o aluno quem aprende. Portanto, traremos, na primeira parte do texto, as principais características no ensino superior com base no pressuposto da mudança de paradigma da centralidade do ensino no professor para a centralidade do ensino no aluno. 
Ao abordar essa mudança, trazemos como reflexão principal a importância do professor como organizador das condições para a construção do conhecimento, e do aluno como sujeito ativo no processo dessa construção por meio da aprendizagem. As implicações disto para a educação são essenciais, pois entrelaçam os processos de vida e de conhecimento numa unidade inseparável.

No segundo momento, tratamos do papel do professor e do aluno no processo de ensino-aprendizagem. A primeira afirmativa apresentada é que não há exclusividade e nem centralidade nem em um nem no outro, porque consideramos que é uma relação que permite a interação simultânea num espaço de diálogo contínuo e consistente, e numa negociação persistente entre os envolvidos.

Nesse sentido, o espaço da aula torna-se promotor da experiência do encontro, possibilitando o desenvolvimento mútuo, o diálogo, o conhecimento numa atividade coletiva. Essa ideia de construção coletiva significa que a realização da aula exige constantes interferências do professor, assim como a participação e o envolvimento do aluno, tornando essas teias interativas cotidianas complexas, porque cada um traz componentes de sua condição humana: afetividade, cognição, vontade, cultura e capacidade de agir sobre o outro.

Por fim apresentamos as considerações finais destacando que tanto o professor quanto o aluno assumem o papel da fala e da partilha na construção e produção do conhecimento promotor numa transformação da realidade.

Portanto, o ato educativo, isto é, a aula, não existe fora das relações sociais, o que nos faz admitir sua complexidade, sua dinamicidade e seus conflitos, requerendo, do professor e do aluno, a criação de um contexto de negociação aberta e permanente que parte da compreensão comum enriquecida constantemente com as contribuições dos diferentes participantes, cada um segundo suas possibilidades e competências. 


\section{A aula e seus desafios na contemporaneidade}

Sem pretensão de conceituar aula, iremos trazer algumas ideias que permearão este artigo. Primeiramente, entendemos aula como processo mediado pela presença, pelo gesto e, sobretudo, pela palavra. Não é qualquer palavra, mas a palavra que possibilita participação, ação e transformação, tanto do professor quanto do aluno. Palavra que fala a linguagem da vida na qual todos se ouvem, se contemplam e se compreendem. Nesse sentido, a aula nos remete à dinâmica da vida, é imbricada na complexidade da realidade e dos sujeitos que a compõem: o professor e o aluno. Isso nos obriga a desfazer da representação que criamos da aula como lugar organizado, padronizado, uniformizado e sem o perigo da subjetividade, para acreditar que ela é feita por meio de todo o movimento que acontece em função da objetividade.

Entendemos que tanto o professor quanto o aluno têm metas a atingir. O primeiro com o intuito de ensinar e o segundo com o de aprender. Nesse sentido, o professor, para garantir o controle de que os alunos estão aprendendendo efetivamente, não só deve apegar-se ao conteúdo como princípio, meio e fim do processo de ensino como, sobretudo, deve usar a experiência do aluno como fonte de inspiração para levar a transformação do conhecimento comum (do dia a dia) para o conhecimento científico, num entrosamento de partilha e troca de ideias entre professor-aluno e alunosalunos.

Tendo em vista a fundamentação acima, trazemos a segunda ideia de que a aula é um desafio. Desafio que emana de ação conjunta, compreensão mútua, construção do conhecimento consciente conjunto e mais ainda um desafio que emana de uma construção de identidade única para cada sujeito. Portanto, aula é ação coletiva, cada um é essencial no enfrentamento ao desafio, não há possibilidade de exclusividade de um ou de outro na dinâmica dela, e nem tão pouco de excluir. Isto porque é esse coletivo que dará à aula a condição de tornar-se um lugar de encontro dos sujeitos que 
vivem e fazem o mundo juntos. Então, a aula deve ser continuidade desse trabalho do homem e da mulher de construirem-se num movimento que desafia o próprio viver criando, em seus sujeitos, o real significado de seu papel histórico e social.

Uma outra ideia é o entendimento que temos de que a aula é o espaço da criatividade. Não há como prescindir do planejar, do se inspirar em experiências próprias e de outros, de se fundamentar em conhecimentos e pesquisas, mas, por ser a aula um lugar vivo e de permanente surpreendimento, é que professor e aluno, por meio das perguntas, de desafios e de ideias divergentes sentem-se impulsionados pela criatividade. A criatividade permite uma atitude de abertura a novas experiências, a ousar, desenvolve o olhar curioso, a confiança em si mesmo e no outro, é o que mantém a pessoa apaixonada pelo que faz. Nesse sentido, há que se compreender que ideias diferentes, o questionamento, o tempo para pensar e testar hipóteses, a curiosidade, o ambiente sem pressões, seguro e amigável, a crítica com cautela e a liberdade são elementos que buscam propiciar o potencial criativo de alunos e professores.

Diante da impossibilidade de se fornecer um guia para realização da melhor aula a criatividade torna-a impulsionadora de descobertas e do lugar privilegiado do ensinar a aprender e do aprender a aprender. Assim, por um lado, quando o professor ensina, está ao mesmo tempo dizendo ao aluno quais as estratégias, as formas, os caminhos mais fáceis para chegar ao conhecimento e, por outro lado, quando esse aluno aprende a chegar ao conhecimento, está aprendendo a ter estratégias próprias para tornar-se autônomo na construção desse conhecimento.

Dessa forma, a aula se estabelece em várias dimensões, é ética ao ser inserida no mundo com seus fatos e atualidades de forma refletida, buscando aporte na filosofia, na sociologia e na antropologia, para suas discussões. É técnica ao apresentar aos alunos as teorias e maneiras práticas de como fazer, de adquirir competências, para apreenderem o conhecimento para o qual se preparam profissionalmente. É humana porque 
se preocupa com o homem, detendo-se em seus desejos e peculiaridades, na forma como se coloca no mundo de forma participativa e transformadora.

Dessa forma também deverá ser dotada da dimensão estética porque sua atuação "[...] não se restringe à escola, à faculdade, à universidade, mas parte para o mundo, para a vida, motivo por que deve ser ela não meramente instrumental, mas humana, estética" (AMORIM; CASTANHO, 2008, p. 107).

O que propomos em relação à dimensão estética da aula é buscar trazer a arte à educação, por meio de experiências estéticas refletidas que possam aproximar os alunos do universo sensível, que lhes permitam estabelecer um vínculo entre si e sua própria subjetividade. Afinal, na contemporaneidade, a esteticidade está abafada pelo marketing onde a beleza e a percepção são utilizadas de forma inescrupulosa e as referências estéticas circunscrevem-se ao que é divulgado pela mídia.

A beleza não está à espera de nós, não é qualidade objetiva dos objetos, é produzida no interior dos seres humanos, nasce de sua consciência, na relação entre o sujeito e o objeto. Para tanto, é necessário provocar os sentidos humanos permitindo-lhes entender os códigos artísticos que são muito diferentes daqueles com os quais estamos acostumados a lidar cotidianamente. São códigos estéticos que modificam nossa maneira de sentir à medida que com eles nos familiarizamos, que tornam nossa própria maneira de ser no mundo mais refinada e sensível às sutilezas de nossa vida interior.

É papel da universidade ampliar os horizontes culturais dos estudantes por meio de um ensino no qual as palavras e atitudes do professor sustentem "[...] sua possibilidade de pôr magia e encanto nos olhos de seus alunos, de ensinar-lhes a olhar o que não foi visto ainda, ou olhar o memso, como se novo fosse" (AMORIM; CASTANHO, 2008, p. 107).

A arte, dessa forma, poderia colocar em suspenso a prontidão, a correria do tempo, as coisas desse mundo carente de compaixão, no qual nos transformamos em consumidores, nos avaliamos face aos outros e não a nós 
próprios, onde nos vemos mais com a autoimagem que projetamos do que com experiência e habilidades que adquirimos.

É não apenas necessário, como também urgente, que a beleza e a educação deem-se as mãos para quebrarem a corrente que insensibiliza o homem contemporâneo, tornando-o cada vez mais ensimesmado e incapaz de se compadecer com os acontecimentos - por vezes brutais - que ocorrem à sua volta. Afinal, é sobre o mundo que agirá a educação que seja formadora humana, por isso a aula torna-se o local onde a beleza deve ser experienciada e encarnada pelos seus sujeitos: aluno e professor.

\section{Principais características de uma boa aula no ensino superior}

Partindo da crença de que estudantes universitários já possuem personalidade formada e sabem o que pretendem, durante muito tempo prevaleceu, no âmbito do ensino superior, a ideia de que o bom professor nesse nível precisaria dispor apenas de capacidade de comunicação fluente embasada por sólidos conhecimentos científicos relacionados à disciplina de sua área de atuação.

Essa é a razão que levou as autoridades educacionais a se preocuparem fundamentalmente com a preparação de pesquisadores, como se quanto mais atuassem como tal, melhores professores pudessem ser. Atualmente essa justificativa tem-se mostrado cada vez mais inaceitável, tendo em vista que o professor, seja ele de qualquer nível de ensino, necessita adquirir sólidos conhecimentos específicos de sua área, mas não pode prescindir de conhecimentos pedagógicas que tornem o aprendizado mais eficaz.

Acresce-se a isso a necessidade de ampliação da visão de mundo, de ser humano, de ciência e de educação como pressupostos vitais em sua função, havendo ainda, as atividades de pesquisa e de administração, que acabam por ocupar precioso espaço de tempo docente, muitas vezes o 
distanciando das atribuições essenciais ao exercício do processo de ensinoaprendizagem.

A esse respeito, LIBÂNEO (2011, p. 191) enfatiza dois problemas recorrentes no ensino universitário:

a) O desconhecimento ou a recusa das contribuições da pedagogia e da didática; b) a separação entre o conteúdo da disciplina que se ensina e a epistemologia e métodos investigativos dessa disciplina. Muitos professores ainda se utilizam da didática tradicional, que se ocupa meramente dos aspectos prescritivos e instrumentais do ensino. Outros não ajudam os alunos a vincular sua aprendizagem ao domínio dos procedimentos lógicos e investigativos da disciplina ensinada.

Dessa forma, a docência universitária tem-se mostrado extremamente contraditória em relação a seus parâmetros de identidade socioprofissional, motivando muitos professores desse nível de ensino a centrarem sua identidade mais em suas especialidades científicas do que em suas atividades docentes, fato que também dificulta a identificação com outros colegas, sejam ou não de sua especialidade. Essa falta de identidade profissional docente é fruto de uma preparação orientada para o domínio científico em detrimento do conhecimento pedagógico para seu exercício.

No que se refere à formação do professor universitário evidenciam-se as deficiências ao se analisar os resultados de avaliações realizadas com alunos de graduação ao longo dos cursos, nos quais têm sido comum apontarem críticas em relação à falta de didática dos professores. Por didática entendemos aqui "o ensino como atividade de mediação para promover o encontro formativo, educativo, entre o aluno e a matéria de ensino, explicitando o vínculo entre teoria do ensino e teoria do conhecimento" (LIBÂNEO, 2011, p. 192).

Em relação aos cursos de Pedagogia, Gatti (2010) chama a atenção para a pouca relevância dada à didática quando traz que apenas 3,4\% das disciplinas ofertadas referem-se à Didática Geral, 20,7\% do currículo se 
preocupa com as metodologias e práticas de ensino específicas e apenas 7,5\% são destinadas aos conteúdos a serem ministrados ou ao "o que ensinar":

Esse dado torna evidente como os conteúdos específicos das disciplinas a serem ministradas em sala de aula não são objeto dos cursos de formação inicial do professor. Disciplinas relativas ao ofício docente representam apenas $0,6 \%$ desse conjunto. É preciso considerar que, na análise realizada sobre o conteúdo das ementas, verifica-se que as disciplinas que estariam mais ligadas aos conhecimentos relativos à formação profissional específica também têm em suas ementas uma predominância de aspectos teóricos, aqueles que fundamentam as teorias de ensino, contemplando muito pouco as práticas educacionais associadas a esses aspectos. As disciplinas deste grupo trazem ementas que registram preocupação com as justificativas sobre o porquê ensinar, o que, de certa forma, contribuiria para evitar que essas matérias se transformassem em meros receituários. Entretanto, só de forma muito incipiente registram o que e como ensinar. (GATTI, 2010, p. 1.368)

Diante disso, como será possivel exigir do docente universitário uma prática inovadora, que seja, ao mesmo tempo significativa e desafiadora para ele e para seus alunos e que, também, por outro lado, acabe por proporcionar-lhe a oportunidade de reconstruir sua prática e consequentemente esse currículo pré-determinado? As disciplinas estanques, desvinculadas da prática e do contexto acabam proporcionando o predomínio da aula expositiva e de seminários ${ }^{4}$, tornando o espaço da sala de aula pouco produtivo para o processo de ensino-aprendizagem.

Zabalza (2004, p. 169) afirma ser necessário transitar da docência centrada no ensino para uma docência mais ambiciosa e prazerosa, a docência baseada na aprendizagem. Essa trajetória exige que os professores compreendam que a aprendizagem constitui um dos primeiros eixos da profissão e, por isso, devem transformar-se em profissionais da "aprendizagem", em vez de "especialistas que conhecem bem um tema e

${ }^{4}$ Seminários como atividade de apenas apresentar resumos de textos lidos pelos alunos. 
sabem explicá-lo, deixando a tarefa de aprender como função exclusiva do aluno".

O autor sugere a unidade dos processos de ensino e aprendizagem, compreendendo-os como condições para a produção do conhecimento, no qual alunos e professores constituem-se parceiros no que se designou por "dupla competência”. Entende-se aqui que essa inovação prática traz a necessidade de o professor universitário tornar interdependente "os processos de ensinar e de aprender" (ZABALZA, 2004, p. 169), vivenciando experiências e conhecimentos do aluno e do seu modo de aprender para poder ensinar. Portanto, é fundamental que se considere o professor como investigador, possibilidade essa que se torna distante, quando constatamos como se distribuem as disciplinas nos cursos superiores, como por exemplo nos cursos de licenciaturas em Língua Portuguesa, em Matemática e em Ciências Biológicas analisadas por Gatti (2011, p. 1.373):

[...] constatou-se que é reduzido o número de disciplinas teóricas da área de Educação (Didática, Psicologia da Educação ou do Desenvolvimento, Filosofia da Educação etc.) e que mesmo as disciplinas aplicadas têm espaço pequeno nas matrizes, sendo que estas, na verdade, são mais teóricas que práticas, onde deveria haver equilíbrio entre estes dois eixos. Com as características ora apontadas, com vasto rol de disciplinas e com a ausência de um eixo formativo claro para a docência, presume-se pulverização na formação dos licenciados, o que indica frágil preparação para o exercício do magistério na educação básica.

Esses dados são preocupantes por se tratarem de cursos de licenciatura dos quais se espera a integração teoria/prática aliada a conhecimentos científicos e pedagógicos. Dito de outro modo, de que maneira é possível inovar na docência universitária sem cair na cilada de que uma aula inovadora é aquela que se utilizam sofisticados aparatos tecnológicos ou que apresenta resultados de pesquisas? 
Certamente que as mudanças ocorridas no cenário mundial devem também ser levadas em conta, já que acarretaram importantes alterações ao trabalho do professor, que necessita tornar-se um organizador da aprendizagem ao invés de mero transmissor de conhecimentos, num contexto em que ocorre fácil acesso à informação, mas no qual seus alunos requerem um ambiente em que a cooperação, o diálogo, a interação e a interlocução sejam mediadores de seu desenvolvimento, para que sejam capazes de vinculá-la à prática profissional.

Também é preciso levar em conta que o ensino é uma "atividade interativa", por isso torna-se fundamental que o docente saiba "identificar o que o aluno já sabe (e o que não sabe e necessita saber)", estabeleça "uma boa comunicação com seus alunos" e saiba "agir de acordo com as condições e características apresentadas pelo grupo de estudantes" (ZABALZA 2004, p. 111), sendo o espaço da aula o encontro, isto é, o lugar onde se estabelecem as relações.

\section{Papel do professor e do aluno no processo de ensino aprendizagem}

Vivemos em um tempo em que a aula universitária requer muito mais do que chegar diante da classe e apresentar novos conceitos ou um conteúdo; torna-se necessário que o professor proponha situações que possam estimular, nos estudantes, atitudes de descoberta como consequência de problemas, para que tenham a oportunidade de formular perguntas diante da complexidade da vida e da multiplicidade de informações que os bombardeiam cotidianamente. Embora a aprendizagem seja inerente ao sujeito, é papel do professor provocar, desestabilizar, suscitar o interesse e a motivação pela busca do conhecimento.

Libâneo (2011, p. 198) baseia-se no metodo dialético para traçar as bases de um bom ensino universitário, com base na formação do pensamento teórico-científico: 
Trata-se de em processo pelo qual se revela a essência, a origem e o desenvolvimento dos objetos de conhecimento como caminho de construção do conceito. Ao aprender um conteúdo o sujeito adquire os métodos e estratégias cognitivas gerais que são intrínsecos a este conteúdo, convertendo-os em procedimentos mentais para analisar e resolver problemas e situações concretas da vida prática. Desse modo, o pensamento teórico se desenvolve no aluno pela formação de conceitos e pelo dominio dos procedimentos lógicos do pensamento que, pelo seu caráter generalizador, permitem sua aplicação em vários âmbitos da aprendizagem. Em outras palavras, para pensar e atuar com um determinado saber é necessário que o aluno se aproprie do processo histórico real da gênese e desenvolvimento desse saber.

Portanto, não será suficiente dominar os conteúdos ou ser um reconhecido pesquisador na área, já que a prática docente refere-se aos alunos e ao modo como é necessário agir para que aprendam, de fato, aquilo que se planeja ensinar-lhes. Se no processo de ensinar e aprender é preciso considerar o aprendente (aquele que aprende), é importante não esquecer que esse sujeito traz para a sala de aula não apenas o aspecto cognitivo, mas também sua cultura, suas emoções, sua subjetividade, seu ser biológico. O estudante, quando vem à sala de aula, vem em sua totalidade, com toda a sua complexidade.

Dessa forma, na aprendizagem de um conceito científico será importante o domínio do processo de origem e desenvolvimento do objeto de conhecimento ao invés de conhecer apenas seu conteúdo formal, ao mesmo tempo em que se desenvolvem as suas relações com a realidade, com o contexto, com o sujeito que aprende.

Segundo Libâneo (2011, p. 193), é necessário atentar-se aos elementos constitutivos do ato didático, tendo em vista que os objetivos, sejam eles gerais ou específicos, deverão traduzir "intenções sociais e políticas do ensino, expressando a dimensão de intencionalidade da ação docente”. Os conteúdos devem implicar "métodos de investigação da ciência ensinada 
(estrutura lógica da matéria)”, não deixando de levar em conta, ainda, sua necessária "adequação às idades; ao nível de desenvolvimento mental dos alunos, aos processos internos de assimilação; aos processos comunicativos na sala de aula; aos significados sociais dos conhecimentos".

No que diz respeito aos métodos e à forma de organização do ensino, ou o "como ensinar", o mesmo autor enfatiza que devem ocorrer em estreita relação com objetivos e conteúdos "por meio dos procedimentos lógicos e investigativos da ciência ensinada" (LIBÂNEO, 2011, p. 193).

As condições das ações didáticas também não devem ser menosprezadas, já que dizem respeito às possibilidades concretas de ensino e de aprendizagem:

\begin{abstract}
Mais especificamente, referem-se às políticas educacionais e diretrizes normativas para o ensino; às práticas socioculturais, familiares, locais; o espaço físico, ao funcionamento da escola como práticas de organização e gestão, o clima organizacional, os meios e recursos didáticos, o currículo, os tempos e espaços; às condições pessoais e profissionais dos professores; às características individuais e socioculturais dos alunos, às disposições internas para estudo e acompanhamento das atividades didáticas, necessidades sociais e aprendizagem; ao relacionamento entre professor e alunos, alunos e colegas (LIBÂNEO, 2011, p. 93).
\end{abstract}

Esses fatores são fundamentais no momento em que se compreende que o processo de ensinar e aprender se dá nas relações sociais. Ao nos preocuparmos com a melhoria da docência, ressalta Masetto (2005, p. 80), "não podemos nos esquecer de que por trás do modo de lecionar existe um paradigma que precisa ser explicitado, analisado, discutido, a fim de que a partir dele possamos pensar em fazer alterações significativas em nossas aulas”. E quais são os paradigmas que perpassam a docência universitária? Em que sentido esses paradigmas podem representar encontros e desencontros na sala de aula na educação superior? 
Em seu texto Docência universitária: repensando a aula, Masetto (2005) trata de dois possíveis paradigmas que podem perpassar a docência universitária: o paradigma do ensino e o paradigma da aprendizagem. Em nossa discussão, trataremos do paradigma da aprendizagem, por entender que o paradigma do ensino se situa na pedagogia tradicional, já de conhecimento comum, não sendo necessária maior ênfase.

Propomos que a ênfase no ensino seja substituída pela ênfase na aprendizagem, alterando a maneira de se conduzir processo pedagógico, procurando compreender o aluno como uma pessoa em desenvolvimento, sem, no entanto, deixar que o professor se demita da sua função de planejador, dirigente e mediador desse processo do desenvolvimento da personalidade do aluno.

Desta forma aula se transforma num o espaço no qual os alunos terão a oportunidade de desenvolver suas capacidades intelectuais (pensar, raciocinar, refletir, analisar, criticar, dar significado, argumentar, produzir e socializar conhecimentos), desenvolver habilidades humanas e profissionais (saber trabalhar em equipe, conhecer fontes de pesquisa, dialogar com profissionais de outras áreas, saber expressar-se etc.) e desenvolver atitudes e valores integrantes à vida profissional (saber da importância da educação continuada, buscar soluções para problemas da profissão, ter conduta ética na condução da atividade profissional, ter responsabilidade social diante da profissão que irá exercer etc.). (MASETTO, 2005, p.80-81)

O que nos é colocado por Masetto, também assumimos como proposta. Apenas procuramos acrescentar que todo o conhecimento construído se relaciona com a convivência humana, com a vida, com a transformação.

Segundo o autor, são considerados pilares para o paradigma da aprendizagem: organização curricular aberta, flexível, contextualizada e interdisciplinar; corpo docente constituído de profissionais com competências de sua área específica de conhecimento e pedagógicas, que 
compreendem que a aprendizagem se realiza num processo de colaboração participação dos diversos sujeitos envolvidos; metodologia que se fundamenta em procedimentos participativos e desafiadores e em constante processo de avaliação.

O aluno passa a ser um agente protagonista da aprendizagem, o que requer por parte dele a "aquisição e domínio de um conjunto de conhecimentos, métodos e técnicas científicas de forma crítica" (MASETTO, 2005, p.85). É pertinente a afirmação do autor, mas para que possamos considerar o protagonismo do aluno será necessário também que haja o protagonismo do professor. Na aula não haverá professor e aluno e sim, sujeitos em interação que produzem, constroem, dialogam na perspectiva da teoria da ação comunicativa de Habermas, isto é, buscando o consenso na fala de todos.

A aula sendo esse espaço proporcionará ao aluno a oportunidade de adquirir uma progressiva autonomia na aquisição de conhecimentos que vão além daqueles que estiveram presentes em sala de aula. Mais ainda, possibilitará o despertar da consciência de que aprender é um processo contínuo que se estende ao longo da vida, muito além do conjunto de conhecimentos suficientes para o exercício profissional.

Reafirmando essa ideia, Veiga (2008, p. 268-269) traz a seguinte reflexão:

O que acontece na aula é muito mais do que a ordem de transmissão e recepção de informação. Não se trata de um processo de ida e volta de informações. [...] A aula é constituída de um sistema complexo de significados, de relações e de intercâmbios que ocorrem num cenário social que define as demandas da aprendizagem.

A aula constitui-se basicamente da interação entre professores, alunos e o conhecimento. Quem são esses alunos e quem são esses professores? Até o momento trazemos como reflexão princípios a serem 
considerados pelo professor ao organizar a aula. Trataremos agora desses sujeitos: professor/aluno.

Os professores universitários têm características e particularidades específicas, são constituídos dos mesmos aspectos humanos que seus alunos. A relação para com o outro significa que ele vê seus alunos diretamente como pessoas, sendo responsável por eles, embora cada um deles seja diferente e tenha expectativas particulares.

\begin{abstract}
Como então conciliar esses componentes relacionais individuais e coletivos? Quanto tempo um professor deve dedicar a um aluno que apresenta certas dificuldades de aprendizagem? Portanto, ensinar é confrontar-se com problemas e dilemas éticos que se tornam ainda mais delicados quando se encontram num contexto de relações face a face (TARDIF, 2005, p. 71).
\end{abstract}

Podemos inferir que o professor lida com a complexidade, mas também o aluno confronta com a singularidade e subjetividade do professor. Nesse sentido, é pertinente conceber que os fatores pessoais, as intencionalidades, as concepções e a história de cada um influenciam o aprender e o ensinar. Para os professores universitários considerar esses aspectos é essencial à dimensão pessoal de como os alunos aprendem, de como compreender em sua mente e coração os conhecimentos desenvolvidos possibilita criar vínculos de colaboração, de compromisso com o outro e com a sociedade.

Os alunos são sujeitos de sua aprendizagem que, no entanto, não depende exclusivamente deles - de sua capacidade ou de seu esforço - mas, também das condições em que se dá o processo. Sendo assim, tornam-se "protagonistas, causa e condição da eficácia dos processos de aprendizagem" (ZABALZA, 2004, p. 197).

Assman (1998, p. 35) já alertava que a equação simplista de que uma boa aprendizagem seria o resultado de um bom ensino e de um estudo disciplinado não corresponde à realidade, isto é, entrou em crise. Acrescenta 
que aprender é um fenômeno complexo da vida que tem como princípio a essência de estar vivo, imerso "desde o plano estritamente biofísico até o mais abstrato plano mental".

Diante do exposto é importante que, tanto o professor quanto o aluno compreendam que o conhecimento não transita de um lado para o outro e nem pode ser estocado de maneira cumulativa. $\mathrm{O}$ conhecimento se constrói sobre a base de uma teia de ações sobre a qual se busca sentido que possibilita ampliá-lo e transformá-lo.

Portanto, a sala de aula é o espaço privilegiado do pensamento vivo e aberto onde circulam mundos de pensamentos diferentes, mas é preciso que aquilo que efetivamente interessa a professores e alunos seja a vitalidade permanente do pensamento. Tal assertiva leva-nos a concluir que não é possível dialogar seriamente sobre o aprender e o ensinar sem discutir e reavaliar os paradigmas historicamente sistematizados.

Como ressaltam Pimenta e Anastasiou (2008, p.173):

A universidade não deve simplesmente adequar-se às oscilações do mercado, mas aprender a olhar em seu entorno, a compreender e assimilar os fenômenos, a produzir respostas às mudanças sociais, a preparar globalmente os estudantes para as complexidades que se avizinham, a situar-se como instituição líder, produtora de ideias, culturas, artes e técnicas renovadas que se comprometam com a humanidade, com o processo de humanização.

No nosso entendimento, dentre as consequências dessa reavaliação de paradigmas pode haver uma instigante alteração na qualidade da ação educativa que, possivelmente, pode ser considerada realmente uma inovação na docência universitária.

\section{Considerações finais}


Diante de toda a reflexão feita anteriormente, constata-se que o professor pode eleger entre duas possibilidades para exercer a sua docência, quais sejam: o processo centrado no ensino ou o processo centrado na aprendizagem.

Caso o educador sustente sua práxis pedagógica no processo centrado no ensino estará posicionando o aluno como sujeito passivo e a centralidade estará sob seu comando, o que imprime ao ato educativo uma situação de hierarquia, na qual surgem autoridades e subalternos. Essa forma de atuação os faz coniventes com a reprodução de um modelo de sociedade desigual, no qual os direitos não são assegurados a todos os cidadãos.

Além da questão do distanciamento e hierarquização da relação professor/aluno, a centralidade no ensino muitas vezes preocupa-se com a transmissão de procedimentos técnicos, não preparando o aluno para pensar sobre seu trabalho, sobre as condições da convivência em sociedade e sobre todo o processo de exploração que geralmente há por trás do processo produtivo

Desse modelo educativo, não podemos esperar posições críticas e criativas sobre a ciência, a sociedade, o conhecimento e a própria profissão, pois será mero reprodutor de uma identidade previamente estabelecida, na qual a autonomia é substituída pela formação de um profissional que apenas executa procedimentos programados num determinado contexto.

Já a ênfase no paradigma da aprendizagem parte do pressuposto de que o conhecimento vivenciado durante o processo formativo torna-se significativo para o aluno. Nessa perspectiva, as experiências de aprendizagem não resultam em realidades fechadas ou conhecimentos definitivos, totalmente delimitados e adquiridos. Pelo contrário, resultam em realidades abertas a revisões porque continuam em estado de busca e descoberta.

Nessa direção, o professor organiza o processo de ensinar e aprender com a proposição de desafios investigativos aos alunos para que o desenvolvimento seja proporcionado da melhor forma possível. Dessa 
maneira, não somente os alunos, mas também o professor deve saber o que está fazendo, o porquê de estar fazendo, e qual é o objetivo que perpassa as ações desenvolvidas.

Respondendo a esses desafios, os professores, em seu trabalho docente, certamente farão da universidade a principal instituição construtora do novo, estando em condições de responder positivamente à sua missão científica, à sua vocação educativa e à sua responsabilidade social. Cabe também dizer que tal missão e vocação reclamam por um estudante consciente de seu papel ativo na aprendizagem.

Concluindo, constata-se que tanto o professor quanto o aluno do ensino superior precisam enfrentar os desafios da realidade, necessitam aprender, a cada dia, como lidar com a concepção de conhecimento concebido como uma contínua reconstrução baseada no diálogo, no respeito real pelas diferenças, pela aceitação fundamentada no entendimento mútuo e em experiências de aprendizagem que justifiquem e requeiram novos modos de pensar, agir e conviver.

\section{Referências}

AMORIM, V. M. de; CASTANHO, M. E. Da dimensão estética da aula ou do lugar da beleza na educação. In VEIGA I. P. A. (Org.). Aula: gênese, dimensões, princípios e práticas. Campinas, SP: Papirus, 2008.

ASSMAN, H. Reencantar a educação: rumo à sociedade aprendente. Petrópolis, RJ: Vozes, 1998.

FÁVERO, A. A., MARQUES, M. Aprender e ensinar na universidade: a docência na perspectiva da epistemologia da aprendizagem. IX ANPED Sul - Seminario de Pesquisa em Educação da Região Sul. Porto Alegre, 2012. Disponivel em: <http://www.portalanpedsul.com.br/admin/uploads/2012/Politica_de_Educacao_Sup erior/Trabalho/05_20_46_343-7367-1-PB.pdf>. Acesso em: 6 set. 2015.

GATTI, B. A. Formação de Professores no Brasil: características e problemas. Revista Educação e Sociedade, Campinas, v. 31, n. 113, p. 1355-1379, out.dez. 2010 Disponível em: <http://www.scielo.br/pdf/es/v31n113/16.pdf.>. Acesso em: 7 set.2015. 
GOMES, L. R. Educação e consenso em Habermas. Campinas: Alínea, 2007.

HABERMAS, J. Teoria de la acción comunicativa. Madri: Taurus, 1987.

LIBÂNEO, J. C. Conteúdos, formação de competências cognitivas e ensino com pesquisa: unindo ensino e modos de investigação. In PIMENTA, Selma Garrido e ALMEIDA, Maria Isabel. Pedagogia Universitaria: caminhos para a formação de professores. São Paulo: Cortez, 2011.

MASETTO, M. Docência Universitária: repensando a aula. In: TEODORO, António; VASCONCELOS, Maria Lucia (Orgs.). Ensinar e aprender no ensino superior: por uma epistemologia da curiosidade na formação universitária. 2 ed. São Paulo: Cortez/Mackenzie, 2005,

PIMENTA, S. G.; ANASTASIOU, L. Docência no ensino superior. São Paulo: Cortez, 2008.

SACRISTÁN, J. G.; GÓMEZ, A I. Pérez. Compreender e transformar o ensino. Porto Alegre: Artmed, 1998.

TARDIF, M.; LESSARD,C. O trabalho docente: elementos para uma teoria da docência como profissão de interações humanas. Petropólis, R.J.: Vozes, 2005

VEIGA, I. P. A. Aula: gênese, dimensões, principios e praticas.Campinas, São Paulo: Papirus, 2008.

ZABALZA, M. A. O ensino universitário: seu cenário e seus protagonistas. Tradução de Ernani Rosa. Porto Alegre: artmed, 2004. 